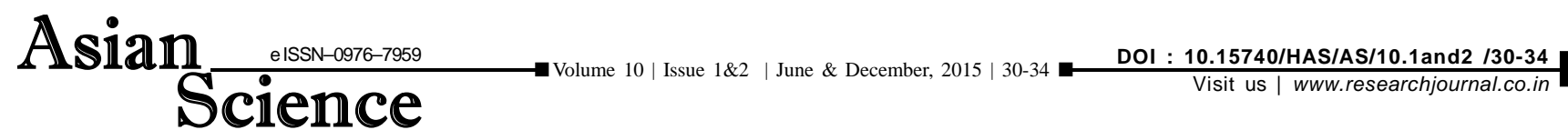

A REVIEW

\title{
Impact of mobile phone radiations on public health
}

\author{
RAMA SHARMA* AND SANJAY SHARMA \\ Department of Chemistry, D.A.V. College, AMRITSAR (PUNJAB) INDIA \\ (Email: sansharma560@gmail.com)
}

\begin{abstract}
Mobile or cellular phones are now an integral part of modern telecommunications, the use of phones is not limited to phone calls only but people are getting various information's and using them for political, civic, health and many more purposes. In many countries, over half the population uses mobile phones. In 2014, there is an estimated 6.9 billion subscriptions globally and this number is going to rise sharply in coming years. In some parts of the world, mobile phones are the most reliable or the only phones available. Due to presence of the large number of mobile phone users, it is important to investigate, understand and monitor any potential public health impact.
\end{abstract}

Key Words : Radiations, Mobile phones, Radio frequency, Cancer

View point paper : Sharma, Rama and Sharma, Sanjay (2015). Impact of mobile phone radiations on public health. Asian Sci., 10 (1\&2): 30-34.

\footnotetext{
* Author for correspondence

Rama Sharma, Department of Computer Science, Hindu College, AMRITSAR (PUNJAB) INDIA (Email: rshca12@ gmail.com)
} 